\title{
SCHILLER E A EDUCAÇÃO ESTÉTICA E REVOLUCIONÁRIA DO HOMEM
}

Jadir Antunes ${ }^{1}$

\section{Resumo:}

Nosso artigo pretende mostrar, em linhas gerais, a concepção de Friedrich Schiller (17591805), filósofo, poeta e dramaturgo alemão de fins do século XVIII, sobre o papel da arte na reeducação moral e política do homem moderno desenvolvida em sua obra Sobre a Educação Estética da Humanidade numa Série de Cartas (1795). Schiller não foi um teórico e defensor da arte como mera contemplação e gozo individual. Schiller não via na arte uma atividade cuja finalidade se encerrava no interior dela mesma. Para Schiller, a arte deveria servir a uma finalidade que a transcendia, a uma finalidade educativa e formadora do intelecto e dos sentimentos humanos. Schiller não acreditava na ciência e nos filósofos e em sua razão fria, calculista e abstrata como os verdadeiros redentores da humanidade. Schiller acreditava, romanticamente, no papel formador e educativo da arte e do artista engajados na construção de um homem e de um mundo reconciliados com os sentimentos, a imaginação, a poesia e a vida de impulsos e criações emanadas do íntimo profundo da natureza.

Palavras-Chaves: Friedrich Schiller (1759-1805). Estética. Romantismo Alemão.

\section{SCHILLER AND THE AESTHETIC AND REVOLUTIONARY EDUCATION OF MAN}

\begin{abstract}
:
Our article intends to show, in general terms, the conception of Friedrich Schiller (17591805), German philosopher, poet and playwright of the late eighteenth century, about the role of art in moral and political reeducation of modern man developed in his work Letters on the Aesthetic Education of Man (1795). Schiller was not a theorist and defender of art as mere contemplation and individual enjoyment. Schiller did not see in art an activity whose purpose was enclosed within itself. For him, art should serve to a purpose that transcends it, an educational purpose that formed human intellect and feelings. Schiller did not believe in

\footnotetext{
${ }^{1}$ Possui Graduação em Economia pela Universidade Estadual do Oeste do Paraná (1999), Mestrado em Filosofia (2002) e Doutorado em Filosofia (2005) pela Unicamp - Universidade Estadual de Campinas SP. É Professor Associado da Unioeste - Universidade Estadual do Oeste do Paraná - na Graduação e no Programa de Mestrado e Doutorado em Filosofia. Tem experiência na área de Ética e Filosofia Política, atuando principalmente em Filosofia Política Moderna e Filosofia Marxista. Email: jdiant@yahoo.com.br. Site pessoal: https://jadirantunes.wordpress.com/.
} 
science and philosophers and in his cool, calculating and abstract reason as the true redeemers of humanity. Schiller romantically believed in the formative and educational role of art and of the artist both engaged in the construction of a man and a world reconciled with feelings, imagination, poetry and the life of impulses and creations emanating from the deepest and innermost of nature.

Key Words: Friedrich Schiller (1759-1805). Aesthetics. German Romanticism.

\section{Introdução}

Nosso artigo pretende mostrar, em linhas gerais, a concepção de Friedrich Schiller, médico, filósofo, poeta e dramaturgo alemão de fins do século XVIII, sobre o papel da arte na reeducação moral e política do homem moderno desenvolvida em sua obra Sobre a Educação Estética da Humanidade numa Série de Cartas.

Schiller (1759-1805) foi, ao lado de Herder, Goethe e Hölderlin, um dos maiores protagonistas do chamado Sturm und Drang alemão, o movimento romântico, poético e antiaristocrático de finais do século XVIII que marcaria profundamente o futuro artístico e filosófico da nascente Alemanha moderna.

Schiller foi um dos grandes pioneiros da crítica da divisão social do trabalho e da consequente formação de um homem abstrato e fragmentado produzido por esta divisão, antecipando em grande medida muito da crítica que mais tarde será desenvolvida por Karl Marx já nos Manuscritos Econômicos Filosóficos de 1844 e principalmente em O Capital em 1867.

McCarthy (2002, p. 26), por exemplo, argumenta que na teoria social de Marx a ideia de um comunismo do futuro organizado segundo as leis da beleza [laws of beauty] teria origem não somente na leitura dos filósofos gregos, mas também nas leituras de Marx de A Educação Estética de Schiller. Como diz também Lucía Bodas Fernández (2010, p. 16), ainda que talvez falar de Schiller como um protomarxista seja um equívoco, isto não implica dizer que não exista uma linha de continuidade entre ele e o projeto marxiano, sendo sobretudo evidente aquela que conduz ao pensamento de Marx dos Manuscritos de Economia e Filosofia. A influência de Schiller sobre o chamado Marx da maturidade pode ser claramente constatada pela leitura das passagens de $O$ Capital que tratam da divisão social do trabalho, do sistema manufatureiro de trabalho, da grande indústria, da

\begin{tabular}{|l|l|l|l|l|}
\hline Qevista Dialectus & Ano 4 & n. 10 & Janeiro - Julho 2017 & p. 61-77 \\
\hline
\end{tabular}


maquinaria e dos efeitos destruidores destes processos sobre a criatividade e a vida individual e sensível do trabalhador.

Schiller foi também mestre e grande influência para o jovem Nietzsche de A Origem da Tragédia. Segundo Assoun (2002, pp. 64-65), a antropologia de Schiller, suas Cartas sobre a Educação Estética do Homem e a ideia de uma oposição entre os dois polos fundamentais do instinto humano, Sachtrieb e Formtrieb, impulso sensível e impulso formal, estariam na base da chamada Kunsttrieb, a teoria dos impulsos estéticos do jovem Nietzsche. Através do jovem Nietzsche, Schiller se expandirá por todo o século XX com Heidegger na Filosofia, Foucault na Sociologia e Freud na Psicanálise. Como diz Paul de Man (1996, p. 130), a força da crítica e da beleza do discurso poético de Schiller ressoará por todo o século XIX na voz de filósofos como Schopenhauer e Nietzsche e até mesmo na voz de Heidegger já no século XX.

Schiller não teria sido somente um dos grandes influentes dos jovens filósofos antimodernos como Marx e Nietzsche, mas, também, de Georg Hegel. Segundo David Leopold (2007, p. 18), o termo dialético Aufhebung, muito familiar para Marx, já era utilizado antes de Hegel por Schiller e Hölderlin. Hegel, inclusive, conclui sua grandiosa Fenomenologia do Espírito citando os versos de Schiller em sua ode à Amizade: "do cálice desse reino dos espíritos espuma até ele sua infinitude" (HEGEL, 2002, p. 545).

Schiller foi também, muito antes de Max Weber, um pioneiro na crítica ao processo de racionalização da ciência e da mecânica e do processo de desencantamento das relações sociais humanas e sua conversão em relações frias, impessoais e abstratas. Segundo muitos intérpretes de Max Weber, Schiller teria sido o verdadeiro inventor da terminologia desencantamento/desenfeitiçamento do mundo [Entzauberung der Welt], largamente utilizada e popularizada por Weber em seus escritos sociológicos. Como diz Antônio Flávio Pierucci (2003, p. 28) acerca do uso desta expressão por Weber: "Weber foi buscá-la nas reflexões estéticas do filósofo e poeta Friedrich von Schiller (1750-1805). Ou, pelo menos, para chegar a ela, em Schiller foi se inspirar".

Schiller foi também uma das grandes influências filosóficas e estéticas para Marcuse e toda a Escola de Frankfurt e um pioneiro na crítica ao processo moderno de formação de um homem cada vez mais unidimensional e do caráter mercantil dos bens

\begin{tabular}{|l|l|l|l|l|}
\hline Qevista Dialectus & Ano 4 & n. 10 & Janeiro - Julho 2017 & p. 61-77 \\
\hline
\end{tabular}


culturais. Como diz Habermas (2008, p. 61): "Herbert Marcuse definiria mais tarde a relação entre arte e revolução em termos similares ao de Schiller".

Schiller não foi um teórico e defensor da arte como mera contemplação e gozo individual. Schiller não via na arte uma atividade cuja finalidade se encerrava no interior dela mesma. Para ele, a arte deveria servir a uma finalidade que a transcendia, a uma finalidade educativa e formadora do intelecto e dos sentimentos humanos. Como diz Fernández (2010, p. 13), "a crítica de Schiller à vida e cultura modernas é mais que evidente ao longo de toda a sua obra, consciente toda ela da ausência de algo, da falta que essa ausência provoca no seio mesmo do homem moderno, assim como na relação deste com a sociedade e com o mundo externo em geral". Segundo Fernández (2010, p. 16), um dos fios condutores principais da linha de pensamento de Schiller não era outro que a insistência constante na urgente realização real e efetiva, e não em um sentido metafísico e moral como aparecia especialmente para Kant, da liberdade dos seres humanos.

Schiller, por sua profundidade e riqueza de pensamento, tem sido interpretado ao longo do tempo ora como um filósofo original romântico e crítico da modernidade, ora como um mero continuador e crítico de Kant e ora como uma espécie de protomarxista, protoweberiano e protomarcuseano. Para além de todas estas tentativas de definições e enquadramentos da obra e do pensamento de Schiller dentro de certos parâmetros exteriores, é preciso pensar Schiller como Schiller, como um homem atormentado pela necessidade romântica e revolucionária de resolver politicamente a cisão e o dilaceramento humano provocados pela emergência da modernidade capitalista.

Schiller não acreditava na ciência e nos filósofos e em sua razão fria, calculista e abstrata como os verdadeiros redentores da humanidade. Schiller também não acreditava no proletariado, como acreditará mais tarde Karl Marx. Para Schiller, o proletariado era uma massa desagregada, fragmentada e destruída esteticamente pelo movimento ensurdecedor das fábricas e da grande indústria. Schiller não poderia ter encontrado no proletariado, como encontrará mais tarde Marx, o sujeito realizador do ideal romântico de liberdade, de uma liberdade integral e total do homem, de uma liberdade não cindida, não abstrata, não fragmentada e não atomizada como a liberdade burguesa, porque o proletariado era ainda uma mera massa amorfa e desagregada no começo do século XVIII na Alemanha, era ainda

\begin{tabular}{|l|l|l|l|l|}
\hline Q & Ano 4 & n. 10 & Janeiro - Julho 2017 & p. 61-77 \\
\hline
\end{tabular}


uma massa em formação e sem a vida orgânica e política do proletariado já conhecido por Marx nas revoluções que tomaram conta da Europa entre os anos de 1830 a 1850. Schiller acreditava, romanticamente, no papel formador e educativo da arte e do artista engajados na construção de um homem e de um mundo reconciliados com os sentimentos, a imaginação, a poesia e a vida de impulsos e criações emanadas do íntimo mais profundo da natureza.

\section{O tratado estético de Schiller}

Sobre a Educação Estética da Humanidade numa Série de Cartas é uma obra publicada por Schiller em 1795 e composta de vinte e sete cartas endereçadas ao duque Frédéric-Christian de Schleswig-Holstein. As cartas schillerianas teriam origem em correspondências realmente endereçadas ao duque entre fevereiro e dezembro de 1793, porém destruídas em um incêndio. A partir do incêndio, Schiller reescreve a correspondência e a publica em forma de livro em 1795. As Cartas são uma tentativa de Schiller de reinstalar no universo humano a unidade e a conciliação entre os impulsos do sentimento e os da razão cindidos e separados entre si pela emergência da modernidade. As Cartas são também uma tentativa de superação das dicotomias morais kantianas que cindiam o homem em dois universos distintos, separados e opostos entre si: o da moralidade e o da felicidade. As Cartas são, assim, uma declaração crítica à chamada Aufklärung alemã e ao processo de padronização e homogeneização instaurado no âmbito da razão humana; são uma condenação ao ideal kantiano de uma vida de ascese fundada sobre a noção de imperativo categórico e da consideração de toda ação pautada nos sentimentos e na busca pela felicidade, como sendo imoral e contrária aos princípios universais da razão. Nesta crítica, segundo Michael Bell (2000, p. 74), Schiller produziu uma das mais belas obras que tratam da relação entre sentimento moral e sentimento estético.

Para Kant, como para todo racionalista e metafísico convicto, a razão possui uma autoridade e um poder natural inquestionáveis sobre todos os impulsos emanados da vida e dos sentidos humanos. A beleza das Cartas de Schiller não consiste em conceder aos sentidos, inversamente, prioridade total em relação à razão, mas, sim, em construir uma

\begin{tabular}{|l|l|l|l|l|}
\hline Qevista Dialectus & Ano 4 & n. 10 & Janeiro - Julho 2017 & p. 61-77 \\
\hline
\end{tabular}


harmonia estética entre os impulsos emanados da razão e os emanados do sentimento. Os grandes construtores desta arquitetura estética não seriam o filósofo e o cientista, mas os futuristas da arte e da poesia, os poetas e artistas inspirados por uma imaginação estética unitária, integral, bela, atemporal, harmônica e não utilitária.

\section{Crítica à Aufklärung}

Schiller começa seu tratado estético criticando o caráter racionalista, abstrato e analítico da filosofia moderna porque ela, segundo ele, assim como a química, só encontra a ligação das diversas partes de um todo mediante a dissolução deste todo em partes cada vez mais simples e menores, porque, ainda, para captar o fenômeno a filosofia deve dilacerar o belo corpo do mundo real em conceitos abstratos e expor tais conceitos num precário esqueleto verbal. Schiller nos diz que a investigação filosófica séria, antes de nos levar a um mundo lógico, abstrato e destituído de beleza e de arte deveria nos levar em direção a ambas e à liberdade política.

Segundo Schiller, a utilidade, isto é, o valor atribuído às coisas pela economia e pelos homens de negócios, a utilidade no sentido de que algo só tem valor quando é mercadoria capaz de ser valorizada e encher o bolso de seu proprietário, é o grande ídolo do tempo. Como diz Schiller (1994, p. 31), "a utilidade [em itálico no original] é o grande ídolo do tempo a quem todas as forças devem ser consagradas e a quem todos os talentos devem homenagear".

Schiller demonstra na crítica ao gosto de seu tempo, isto é, ao gosto artístico desenvolvido pelo capitalismo nascente, o quanto a arte verdadeira e a sociedade capitalista teriam se tornados incompatíveis entre si. Segundo Schiller, o caráter deteriorado do gosto e o caráter mercantil da sociedade teriam se transformados em forças incompatíveis com a arte verdadeira, a arte do belo atemporal, a arte do belo universal que lança a apreciação e os sentidos estéticos do homem para além de um mundo prático e utilitário, para a arte que educa os homens para uma vida estilizada pela beleza e pela perfeição da existência.

Os limites impostos à verdadeira arte do belo não surgem, contudo, apenas do gosto deteriorado e do poder utilitário do dinheiro, mas, ainda, do processo cada vez mais profundo de racionalização da sociedade. $\mathrm{O}$ progresso moderno trazido pela razão não

\begin{tabular}{|l|l|l|l|l|}
\hline Qevista Dialectus & Ano 4 & n. 10 & Janeiro - Julho 2017 & p. 61-77 \\
\hline
\end{tabular}


encerra apenas a fé e o sentimento religioso dentro de fronteiras cada vez mais estreitas, como acreditava o movimento iluminista. O progresso da razão encerra, também, dentro destes limites, a imaginação e todas as faculdades estéticas criativas necessárias para o desenvolvimento de uma arte verdadeiramente bela e livre. Deste modo, diz Schiller (1994, pp. 30-31), "nessa grosseira balança, o mérito espiritual da arte não tem qualquer peso e esta, privada de todo estímulo, desaparece do ruidoso mercado do século”.

Com a mercantilização em massa da sociedade trazida pelo capitalismo, o mérito espiritual da arte cede lugar ao mérito do valor de troca da mercadoria. Com a mercantilização da sociedade e da arte, o mérito espiritual e estético da arte cede lugar ao mérito do comércio e do dinheiro. Com a mercantilização social a obra de arte não será mais avaliada por seu valor estético intrínseco, mas, sim, pelo valor atribuído pela economia e as relações de mercado. Nesta grosseira balança entre arte verdadeira de um lado e dinheiro e racionalização de outro, "mesmo o espírito de investigação fillosófica arrebata à imaginação uma província após a outra, e as fronteiras da arte estreitam-se quanto mais a ciência expande seus limites”, diz Schiller (1994, p. 21).

\section{A oposição entre estado de natureza e estado civil}

A partir da noção contratualista de que antes do estado civil dominado pela lei e a moralidade antecedera o estado natural dominado pelos instintos e a força, Schiller demonstrará a necessidade de se buscar um terceiro estado de caráter ético, ou estético, para se superar as antinomias do progresso capitalista.

No estado de natureza, diz Schiller, os homens viviam fora da moralidade e da lei. Contudo, se neste estado primitivo faltavam-lhes a lei e a moralidade e os homens agiam motivados unicamente por instintos e forças físicas, no estado civil dominado pela lei e a moralidade, os homens se converteram em homens abstratos destituídos de conteúdo, se converteram em autômatos da lei e da moralidade. Se no estado de natureza os homens se relacionavam diretamente como homens reais e determinados, como homens motivados por instintos e forças físicas, no estado civil eles se relacionam apenas abstrata e

\begin{tabular}{|l|l|l|l|l|}
\hline Qevista Wialectus & Ano 4 & n. 10 & Janeiro - Julho 2017 & p. 61-77 \\
\hline
\end{tabular}


contratualmente, isto é, como homens de negócios que só aceitam como verdadeiro aquilo que está dito na lei e nos contratos.

Se a razão dá aos homens a lei positiva e a moralidade universal do estado civil, ela arranca deles o que há de real e efetivo na sua natureza: a força e os instintos. Em nome da repressão à ingovernabilidade dos instintos, o estado civil retira do homem natural o que ele tem de real para lhe encerrar na esfera abstrata e vazia do dever-ser, "ela [a razão] tira ao ser humano algo que ele realmente possui [força e desejos], e sem o qual nada possui, remetendo-o para algo que ele poderia e deveria possuir", diz Schiller (1994, p. 32).

A razão, assim, antes de elevar o homem acima do estado de natureza, o rebaixa para aquém dele. No estado de natureza o homem é um ser vivo e real dotado de faculdades naturais e criativas. Nele, por carecer da razão, o homem teria vivido como um ser inferior, como um não-ser, dominado pelas fantasias dos instintos. No estado civil, ele deverá viver como um dever-ser, como um ser moral dotado de racionalidade. Enquanto o homem físico é real, o homem ético dos contratos e da lei é apenas hipotético.

Enquanto o homem físico se encontra ainda dominado pela força da matéria natural que o constitui, o homem moral se encontra dominado pela idéia abstrata do dever-ser que nunca se realiza plenamente. Entre não-ser e dever-ser, por isso, o homem moderno oscila de um lado a outro em constante tensão e desequilíbrio. Nesta tensão e desequilíbrio entre homem físico e real e homem ético e hipotético, o homem abstrato moderno cambaleia de um lado a outro sem um ponto seguro para se apoiar.

\section{O estado estético do futuro}

Schiller não acredita que uma humanidade verdadeiramente ética possa surgir de um destes polos em desequilíbrio. Para ele é preciso encontrar um terceiro caráter que concilie os dois polos em conflito. Este terceiro caráter conciliador, que Schiller chama de caráter estético, deveria "separar a arbitrariedade do caráter físico e a liberdade do caráter moral; tratar-se ia de afastar aquele um pouco mais da matéria e de aproximar este mais dela" (SCHILLER, 1994, p. 33).

\begin{tabular}{|l|l|l|l|l|}
\hline Qevista Dialectus & Ano 4 & n. 10 & Janeiro - Julho 2017 & p. 61-77 \\
\hline
\end{tabular}


Este terceiro caráter estético deveria proporcionar "uma transição entre o domínio das meras forças e o domínio das leis e que, sem impedir o desenvolvimento do caráter moral, servisse antes de penhor sensível à ética invisível" (SCHILLER, 1994, p. 33). No estado de natureza, estado onde domina o caráter físico e instintivo do homem, o homem se torna um selvagem. No estado civil, o estado civilizado dominado pela moralidade e a lei, o homem se torna um bárbaro, isto é, um homem piorado e deteriorado em relação ao homem selvagem do estado de natureza.

Por homem selvagem, Schiller entende aquele homem que vive dominado pelos instintos e desejos selvagens. Por homem bárbaro, entende todo homem que escarnece de seus instintos e desejos naturais para viver uma vida metafísica, artificial, puramente moral e abstrata. "O selvagem despreza a arte e reconhece a natureza como sendo o seu soberano ilimitado; o bárbaro escarnece da natureza e desonra-a, mas, mais desprezível do que o selvagem, continua frequentemente a ser o escravo do seu escravo", diz Schiller (1994, p. $35)$.

O selvagem, mergulhado na natureza e ignorante da moralidade, escarnece desta e vive segundo seus caprichos e desejos imorais. O homem bárbaro, o homem civilizado pelos contratos, em nome da razão, da moralidade e da lei, escarnece de todos os seus instintos e desejos naturais. O homem se deteriora em bárbaro "quando seus princípios [morais] destroem os seus sentimentos" (SCHILLER, 1994, p. 35). Nesta oposição entre selvagem e bárbaro surge o homem cultivado, o homem educado pela arte do belo e da verdade, o homem estético do futuro, o homem do estado estético. "O homem cultivado faz da natureza sua amiga e honra a sua liberdade, refreando apenas a sua arbitrariedade" (SCHILLER, 1994, p. 35).

O homem selvagem é inimigo da racionalidade, já que a desconhece. O bárbaro é inimigo dos instintos e desejos naturais que, em nome da moral e da racionalidade, os reprime, bloqueia e sacrifica. O homem não dilacerado pelo dualismo contratualista, o homem cultivado pela arte, contudo, é amigo tanto da razão quanto dos sentimentos e procura conciliá-los harmoniosamente. A existência deste homem cultivado pela arte, deste modo, não pode se realizar dentro desta dicotomia entre estado natural e estado civil, mas unicamente num terceiro estado, o estado ético e estético do futuro.

\begin{tabular}{|l|l|l|l|l|}
\hline Qevista Dialectus & Ano 4 & n. 10 & Janeiro - Julho 2017 & p. 61-77 \\
\hline
\end{tabular}


Schiller acredita que todo ser humano individual nasce com uma disposição natural para a pureza e o ideal. A grande tarefa da existência humana consistiria em adequar esta disposição natural com a existência real. No estado de natureza, esta disposição natural ficava impedida de se realizar porque, como ser natural e físico, o homem desconhecia a moralidade e a lei. No estado civil, esta adequação é reprimida pela moralidade e a racionalidade da filosofia e da ciência.

Mais ainda, no estado civil esta adequação entre as disposições de nosso ser natural com nosso ser social é impedida pelo crescente processo de racionalização do trabalho, pelo crescente processo de divisão social das ocupações, pela ética materialista e utilitarista, isto é, pela ética que vê o semelhante como meio e nunca como fim das relações humanas, pela selvageria das classes mais empobrecidas, pela letargia do caráter das classes mais elevadas da população e pelo desenvolvimento das carências econômicas mesmo em meio a mais abundante riqueza material. A adequação entre nossa disposição natural para a pureza e a idealidade e nossa existência física e real é bloqueada na sociedade moderna pelo constante dilaceramento de nosso ser em todas as dimensões da vida social e psíquica.

\section{O dilaceramento do homem moderno}

Schiller mostra, ao longo de suas Cartas, os vários aspectos deste dilaceramento provocado pela modernidade que impede esta adequação entre nossa disposição natural e nosso ser real e permite somente um desenvolvimento unilateral do homem. Este dilaceramento poderia ser observado na oposição entre as duas camadas principais da sociedade.

No polo das chamadas classes inferiores e mais numerosas, a classe trabalhadora e o campesinato da época de Schiller, "somos confrontados com impulsos rudes e sem lei, que após a dissolução dos vínculos da ordem civil se soltam e apressam, numa fúria incontida, a consumar a sua satisfação animal" (SCHILLER, 1994, p. 36). Esta camada da população, rebaixada ao nível do trabalho manual, mecânico e repetitivo, rebaixada ao nível da luta diária pela sobrevivência, "em lugar de apressar-se a ascender à vida orgânica, recai no reino elementar", diz Schiller (1994, p. 36).

\begin{tabular}{|l|l|l|l|l|}
\hline Q & Ano 4 & n. 10 & Janeiro - Julho 2017 & p. 61-77 \\
\hline
\end{tabular}


Se as classes mais baixas da população oferecem o espetáculo da violência e da desumanidade, as classes mais elevadas, por sua vez, não oferecem um espetáculo melhor, mas, ao contrário, oferecem "o espetáculo ainda mais repugnante de letargia e depravação do caráter" (SCHILLER, 1994, p. 36). As classes mais elevadas, antes de desenvolverem seu espírito mergulhado na mais refinada e elevada cultura iluminista, apegam-se a uma ética utilitarista sem limites, à ética do dinheiro e da mercadoria. A cultura, longe de libertar os homens do domínio da ética do dinheiro e da mercadoria, "apenas desenvolve, com cada força que forma em nós, uma nova carência”, diz Schiller (1994, p. 37).

A cultura moderna, a cultura da propaganda da mercadoria, antes de satisfazer nossas necessidades mais eminentes, apenas desenvolve sempre mais novas e supérfluas necessidades e com elas, um homem agoniado sempre carente e desejoso de novas mercadorias, um homem cada vez mais encantado pelas seduções do dinheiro, um homem com o gosto estético degradado pelo efêmero e fútil da mercadoria. $\mathrm{O}$ homem moderno oscila, deste modo, diz Schiller (1994, p. 37), "entre perversidade e brutalidade, entre desnaturalidade e natureza simples, entre superstição e descrença moral".

O dilaceramento do homem moderno pode também ser expresso na contradição entre indivíduo e gênero humano. Schiller, bem ao estilo romântico, acredita que entre os gregos havia unidade entre indivíduo e gênero humano. O primeiro desenvolvia suas capacidades pessoais na mesma medida em que se desenvolviam as capacidades do gênero. No mundo moderno, porém, tudo aparece ao contrário. Nele, gênero e indivíduo se desenvolvem em sentidos antitéticos. Enquanto o gênero se eleva cada vez mais acima do domínio das forças cegas e misteriosas da natureza, o indivíduo recai a níveis próximos da animalidade e da selvageria.

O indivíduo, pelo processo cada vez mais crescente de divisão social do trabalho se desenvolve como indivíduo-fragmento "de tal modo que se tem de questionar os indivíduos um por um para reconstituir a totalidade da espécie" (SCHILLER, 1994, p. 39). Como indivíduo-fragmento e unilateral, o homem se desenvolve como uma substância isolada e anti-social. Contudo, diz Schiller, não apenas indivíduos isolados, mas "classes humanas inteiras desenvolvem apenas uma parte das suas disposições, enquanto outras, como plantas deformadas, se vêem meramente sugeridas por tênues traços" (SCHILLER, 1994, p. 38).

\begin{tabular}{|l|l|l|l|l|}
\hline Qevista Dialectus & Ano 4 & n. 10 & Janeiro - Julho 2017 & p. 61-77 \\
\hline
\end{tabular}


As imagens sugeridas por Schiller mostram quão profundamente o homem individual moderno precisou descer para permitir certo desenvolvimento tecnológico, científico e material do conjunto da espécie. Enquanto uma parte minoritária e insignificante se elevou e desfrutou do progresso material e espiritual, a imensa maioria da humanidade descera ao nível da existência meramente vegetativa e animal.

\section{O indivíduo fragmento}

Este dilaceramento e oposição no interior do gênero humano tem origem na divisão social do trabalho e na própria cultura ocidental. A divisão social do trabalho, e a crescente especialização e unilateralização do trabalhador, a formação do indivíduo-fragmento e sua submissão a esta divisão social, produziu, diz Schiller (1994, p. 39), "um artificioso mecanismo no qual se forma, a partir da junção de um número infinito de partes sem vida, uma vida mecânica na sua totalidade”.

Com o trabalho de fábrica e o trabalhador preso a uma linha de produção que ele não controla, o trabalho torna-se um fardo monstruoso que deforma a consciência e o corpo do trabalhador: "eternamente agrilhoado apenas a um pequeno fragmento isolado do todo, o ser humano especializa-se apenas como fragmento" (SCHILLER, 1994, p. 39). E como homem-fragmento separa-se das conquistas gerais da espécie, desfrutando, no melhor dos casos, apenas de um pequeno fragmento delas, quando não desce abaixo do nível médio de existência da humanidade, vivendo como animal.

Schiller, como um dos primeiros representantes do romantismo na filosofia, não deixa de criticar, em nome dos progressos materiais do conjunto, o processo de destruição da vida individual, psicológica, sensível e concreta dos indivíduos e sua conversão em homem massa, em homem padronizado pela mercadoria e a grande indústria. A grande indústria e o mercado são incompatíveis com uma vida humana individual, sensível e concreta, a produção em massa e em larga escala da grande indústria é incompatível com as necessidades individuais e, por isso, os homens são constantemente convertidos em homens de gosto médio, genérico e abstrato, em homens com o gosto eclético e indeterminado da mercadoria.

\begin{tabular}{|l|l|l|l|l|}
\hline Q & Ano 4 & n. 10 & Janeiro - Julho 2017 & p. 61-77 \\
\hline
\end{tabular}


O processo racionalizador da sociedade moderna baseado na ciência, na técnica, na especialização e na particularização dos ofícios é visto por Schiller como causa fundamental do dilaceramento humano. Com este processo, diz ele, "se destrói gradualmente a vida individual concreta, para que a abstração do todo cumpra a sua precária existência, e o Estado mantém-se estranho aos seus cidadãos, uma vez que o sentimento nunca entra em contato com ele" (SCHILLER, 1994, p. 40).

O homem de espírito especulativo, o homem das luzes, com seus métodos abstratos e racionalizadores "tornou-se forçosamente um estranho no mundo dos sentidos, perdendo a matéria em favor da forma" (SCHILLER, 1994, p. 40). O homem de espírito prático, por sua vez, "encerrado num círculo uniforme de objetos e ainda mais limitado dentro do mesmo por meio de fórmulas, perdeu de vista a liberdade do todo, empobrecendo juntamente com a esfera" (SCHILLER, 1994, p. 40).

Nestas antíteses, o homem de espírito especulativo "cai na tentação de modelar o que é real de acordo com o que é pensável" (SCHILLER, 1994, p. 40), enquanto o homem de espírito prático avalia toda sua sabedoria "de acordo com um fragmento experiencial específico e pretendendo adaptar as regras da sua tarefa a qualquer tarefa indiferenciadamente" (SCHILLER, 1994, pp. 40-41). O homem especulativo, com suas abstrações universalizadoras "se elevara demasiado em relação ao indivíduo isolado" (SCHILLER, 1994, p. 41), enquanto o homem de espírito prático, o homem comum, "descera demasiado em relação ao todo" (SCHILLER, 1994, p. 41). Nestas antíteses, a abstração filosófica deve necessariamente "roubar à fantasia a sua energia e o seu fogo" (SCHILLER, 1994, p. 41) e converter o pensador abstrato num homem de coração frio e insensível, enquanto o homem comum, encerrado num círculo uniforme, repetitivo e mecânico de trabalho é convertido num homem de imaginação limitada e de coração estreito.

\section{A fuga através da arte}

O caráter fatalista e dilacerante do progresso, que afasta o indivíduo da espécie e converte a especialização e a unilateralização em maldições, poderia ser evitado, na

\begin{tabular}{|l|l|l|l|l|}
\hline Q & Ano 4 & n. 10 & Janeiro - Julho 2017 & p. 61-77 \\
\hline
\end{tabular}


concepção de Schiller, pela fundação de um novo estado estético. Tem por isso, diz Schiller (1994, p. 43), "de estar ao nosso alcance a possibilidade de restabelecer essa totalidade na nossa natureza, depois de ter sido destruída pelo artifício, através de uma arte superior".

Como representante alemão do romantismo filosófico, Schiller advoga a necessidade de retornarmos a um estado de vida mais simples e natural fugindo, assim, da degradação do progresso capitalista. Tal fuga principiaria, por um lado, "furtando-se à violência cega da natureza e por outro regressando à sua simplicidade, verdade e plenitude" (SCHILLER, 1994, p. 43).

Esta fuga da civilização moderna fundada pelo capitalismo não seria exatamente uma fuga em direção a formas passadas de existência, às formas decadentes da Idade Média europeia e ainda à vista de Schiller no fim do século XVIII. Esta fuga seria uma fuga em direção ao futuro, em direção a um estado estético que conciliaria todos estes elementos opostos e dilacerantes do progresso numa harmonia bela e perfeita. Esta fuga em direção ao futuro seria uma fuga aberta pela arte verdadeira, pela arte que tem como fim a educação estética da humanidade, a educação do homem para valores verdadeiramente humanos e determinados, para valores que considerem o homem individual como um ser com necessidades específicas e não com as necessidades abstratas, gerais, ecléticas e indeterminadas do mundo da mercadoria.

A execução da tarefa de arrancar os homens do estado de barbárie da sociedade moderna não seria levada a cabo, segundo o entendimento de Schiller, nem pelas chamadas classes inferiores da sociedade, isto é, pela classe trabalhadora e camponesa, nem pelas chamadas classes superiores, as classes enriquecidas, porque enquanto a primeira classe, segundo Schiller, está afundada na luta pela simples sobrevivência, a segunda está atolada na ética utilitarista do mercado, na concorrência e na luta por mais dinheiro. Como diz ele: "a razão cumpriu o que pode cumprir ao encontrar e enunciar a lei; a execução desta tem de estar a cargo da corajosa vontade e do sentimento vivo" (SCHILLER, 1994, p. 44).

Se a razão encontrou a lei, a arte do belo deve executá-la. Por isso, "o caminho para a cabeça tem de ser aberto através do coração" (SCHILLER, 1994, p. 45). Dado o predomínio da faculdade pensante frente à faculdade de sentir, dado o predomínio da razão sobre o coração, dado o embotamento cerebral e a calcificação de nossos sentimentos, "a

\begin{tabular}{|l|l|l|l|l|}
\hline Qevista Dialectus & Ano 4 & n. 10 & Janeiro - Julho 2017 & p. 61-77 \\
\hline
\end{tabular}


formação da capacidade de sentir constitui assim a mais urgente carência do tempo" (SCHILLER, 1994, p. 45). Urgência que deverá ser cumprida pela arte do belo verdadeiro.

\section{$O$ artista da beleza}

A tarefa de arrancar o homem do estado de degradação moderna só poderia ser executada pelo artista do belo com a condição de que não seja filho de seu próprio tempo, com a condição de que tire suas formas de beleza e perfeição a partir de formas puras e ideais, de formas atemporais não corrompidas pelo tempo. "Embora o artista seja filho do seu tempo, grave seria para ele se fosse simultaneamente o seu discípulo ou mesmo o seu favorito" (SCHILLER, 1994, p. 46).

Se o artista expressar uma arte ao gosto de seu próprio tempo, o gosto utilitário, só poderá expressar uma arte corrompida, já que os homens da sociedade moderna, em sua absoluta maioria, como homens dominados pelo tempo, cultuam o gosto do mercado, o gosto do bizarro e do disforme, o gosto médio massificado e uniforme adequado à produção de mercadorias em larga escala.

Para produzir uma arte verdadeira, o artista do belo deveria elevar-se acima de seu próprio tempo e produzir uma arte regeneradora, uma arte que elevasse moral e culturalmente os homens, uma arte da interioridade que reconciliasse o homem interior e espiritualmente, uma arte que reunisse novamente no interior do homem individual e do homem social a animalidade e a sociabilidade imanentes do homem, que reunisse o impulso desmedido dos instintos com as medidas e limites do racional, e não a arte da exterioridade, a arte da propaganda e do estímulo selvagem ao consumo como é a arte da mercadoria. Do presente, o artista deveria extrair apenas a matéria para a arte, enquanto as formas do belo deveriam ser extraídas de um tempo futuro mais nobre culturalmente, de um tempo futuro conhecido apenas pela imaginação poética e pelo gênio do artista, por aquele que consegue se elevar acima de seu próprio tempo e vislumbrar com o coração e os sentimentos um tempo futuro mais belo e perfeito. "É certo [que o artista] irá extrair a matéria do presente, mas tomará de empréstimo a forma de um tempo mais nobre, e mesmo para além de todos os tempos, da unidade absoluta de seu ser”, diz Schiller (1994, p. 46).

\begin{tabular}{|l|l|l|l|l|}
\hline Qevista Dialectus & Ano 4 & n. 10 & Janeiro - Julho 2017 & p. 61-77 \\
\hline
\end{tabular}


Um artista com esta capacidade só poderia ser um artista cuja imaginação sobre o modo de vida humano do futuro transcendesse os domínios abstratos e fechados da imaginação moderna.

Ao contrário das classes baixas ou elevadas da sociedade, o artista do belo seria o único que poderia transcender seu próprio tempo, porque seria o único que não teria sido corrompido por ele e que ainda conservaria a unidade indivisível e interior do homem enquanto homem, segundo Schiller. Todas as outras formas de existência do homem, por existirem como formas abstratas e por sofrerem a cisão destruidora do progresso, por estarem submetidas ao domínio do tempo, da utilidade e da necessidade, estariam incapacitadas de elevar a humanidade a um nível superior mais belo e perfeito de existência. O artista do belo seria o único, segundo Schiller, que poderia, por meio da sua arte, libertar a humanidade da maldição dilacerante do progresso capitalista porque "do puro éter da sua natureza demoníaca, corre a fonte da beleza, não contaminada pela depravação das gerações e tempos que se revolvem muito mais para o fundo em redemoinhos turvos" (SCHILLER, 1994, p. 46).

$\mathrm{O}$ artista do belo seria o único que poderia realizar tal tarefa, porque é o único homem não comprometido com o real das abstrações filosóficas, mas, sim, com o ideal e possível da arte do belo verdadeiro. A esfera do real deveria ficar a cargo do entendimento filosófico, "que aqui se encontra em casa própria" (SCHILLER, 1994, p. 47), enquanto o artista se empenharia "em produzir o ideal a partir de uma visão do possível com o necessário" (SCHILLER, 1994, p. 47), a partir dos jogos de sua imaginação criadora. O verdadeiro artista do belo daria aos homens, portanto, aquilo que eles necessitam e não aquilo que seus instintos insensíveis e embrutecidos esteticamente louvam e degustam.

"Vive com o teu século, mas não sejas a sua criatura, proporciona aos teus contemporâneos aquilo de que necessitam, não aquilo que eles louvam", diz Schiller (1994, p. 48) aos artistas e arquitetos de um novo tempo. Dá aos homens e ao mundo no qual atua, diz Schiller, a orientação para o bem, a beleza e a perfeição de uma época futura. "Onde quer que os encontres, rodeia-os de formas nobres, grandes, inteligentes; cerca-os de símbolos de perfeição, até que a aparência supere a realidade e a arte a natureza", diz Schiller (1994, p. 49) aos jovens e futuros artistas educadores da humanidade, aos jovens e

\begin{tabular}{|l|l|l|l|l|}
\hline Q & Ano 4 & n. 10 & Janeiro - Julho 2017 & p. 61-77 \\
\hline
\end{tabular}


futuros artistas revolucionários, inimigos do poder corruptor do dinheiro e do gosto bizarro, desmedido, disforme e eclético da mercadoria.

\section{Referências Bibliográficas:}

ASSOUN, P-L. Freud and Nietzsche. New York: Continuum, 2002.

BELL, M. Sentimentalism, Ethics and the Culture of Feeling. Capítulo: Friedrich Schiller and the Aestheticizing of Sentiment. New York: Palgrave Macmillan, 200.

FERNÁNDEZ, L. B. Autonomía y emancipación. Sobre la propuesta estético-educativa de Friedrich Schiller y la dialéctica de la Ilustración. In: Boletín de Estética - 14 . Buenos Aires, Junio de 2010.

HABERMAS, J. El discurso filosófico de la modernidad. Capítulo: Excurso sobre las Cartas de Schiller acerca de la educación estética del hombre. Buenos Aires: Katz Editores, 2008.

HEGEL, G. W. F. Fenomenologia do Espírito: Petrópolis: Editora Vozes, 2002.

LEOPOLD, D. The Young Karl Marx: German Philosophy, Modern Politics and Human Flourishing. Oxford: Mansfield College, July 2007.

MAN, P. Aesthetic Ideology. Capítulo: Kant and Schiller. Minneapolis: University of Minnesota Press, 1996.

McCARTHY, G. E. Classical Horizons: The Origins of Sociology in Ancient Greece. New York: State University of New York Press, October, 2002.

PIERUCCI, A. F. O desencantamento do mundo. São Paulo: Editora 34, 2003.

SCHILLER, F. Sobre a Educação Estética da Humanidade numa Série de Cartas. Lisboa: Imprensa Nacional/Casa da Moeda, 1994. Tradução do alemão por Teresa Rodrigues Cadete.

\begin{tabular}{|l|l|l|l|l|}
\hline Qenista Dialectus & Ano 4 & n. 10 & Janeiro - Julho 2017 & p. 61-77 \\
\hline
\end{tabular}

